\title{
AVALIACÃO DE SETE GRAMÍNEAS DE ESTAC̄̃̃O QUENTE PARA PRODUÇÃO DE CARNE NOS CAMPOS GERAIS DO PARANÁ ${ }^{1}$
}

\author{
SÉRGIOROBERTOPOSTIGLIONI²
}

\begin{abstract}
RESUMO - Com o objetivo de verificar a performance animal, capacidade de suporte e produção de carne no período de três anos, sete gramíneas de estação quente foram avaliadas em sistema de pastejo contínuo, com novilhos mestiços Canchim, na região dos Campos Gerais do Paraná. As espécies estudadas foram hemártria Flórida, hemártria Roxinha, capim-do-nilo, capim IPEAME, setária Kazungula, braquiária Marandu e coastcross-1. O delineamento experimental utilizado foi o de blocos casualizados, com duas repetições, adotando-se a técnica de pastejo put and take. Capim-do-nilo e hemártria Flórida apresentaram maiores valores de DIVMS e proporcionaram os melhores ganhos diários por animal. Hemártria Roxinha proporcionou maior disponibilidade de forragem suportando maior número de animais por unidade de área. Hemártria Flórida, capim-do-nilo e hemártria Roxinha produziram os maiores ganhos de peso vivo por hectare, com produções semelhantes de carne. Exceto hemártria Roxinha e capim IPEAME, todas as gramíneas apresentaram declínio nas produções por unidade de área ao longo dos três anos de estudo.
\end{abstract}

Termos para indexação: forrageiras tropicais, forrageiras subtropicais, gado de corte, ganho animal, pastejo.

\section{EVALUATION OF SEVEN WARM SEASON GRASSES FOR BEEF PRODUCTION IN THE CAMPOS GERAIS, PARANÁ, BRAZIL}

\begin{abstract}
With the objective to compare animal performance, carrying capacity and productivity in the period of three years seven warm season grasses were evaluated under continuous grazing, with crossbred Canchim steers, in the region of Campos Gerais, Paraná, Brazil. The grasses studied were Flórida limpograss, Roxinha limpograss, Kazungula setária, brachiaria Marandu, Nilegrass, Ipeamegrass and coastcross-1. Experimental design was in randomized blocks with two replications and the adoption of the put and take method. Nilegrass and Florida limpograss had the highest IVDMD and produced the highest daily gains per steer. Roxinha limpograss produced the greater forage yield and supported more animals per hectare. Florida limpograss, Nilegrass and Roxinha limpograss had the greatest liveweight gains per hectare, with similar beef production. Except for Roxinha limpograss and Ipeamegrass, all the grasses exhibited a marked decline in productivity during the evaluation.
\end{abstract}

Index terms: tropical forages, subtropical forages, animal gain, beef cattle, grazing.

\section{INTRODUÇÃO}

Os Campos Gerais do Paraná têm se caracterizado como uma região de cria de bezerros para serem terminados nas regiões norte e noroeste do Estado. Tal fato está relacionado com o sistema de produção

\footnotetext{
${ }^{1}$ Aceito para publicação em 28 de maio de 1999.

${ }^{2}$ Eng. Agrôn., M.Sc., Dep. de Zootecnia e Tecnologia de Alimentos da UEPG, Caixa Postal 992, CEP 84001-970 Ponta Grossa, PR. E-mail: sergio@lepus.celepar.br
}

adotado pelos produtores, em que a alimentação básica dos rebanhos é feita em pastagens nativas, as quais apresentam estacionalidade na produção, limitado desempenho animal e baixa produção por área (Postiglioni \& Picanço, 1979). Embora o melhoramento dessas pastagens possa ser feito, conforme demonstram os resultados do trabalho conduzido por Postiglioni (1995), essa prática ficaria mais restrita à fase de cria de bezerros, pois dificilmente seria rentável realizar recria e terminação nas pastagens nativas dessa região.

As pesquisas têm demonstrado que espécies subtropicais dos gêneros Paspalum, Hemarthria e 
Cynodon apresentam um bom potencial forrageiro quando cultivadas na região dos Campos Gerais do Paraná, sendo alternativas para melhorar a oferta de forragem para os animais em regime de pastejo (Postiglioni, 1983, 1984). Em sistema de pastejo contínuo na mesma região, Postiglioni \& Picanço (1979), avaliando espécies do gênero Paspalum e Cynodon, verificaram que é possível a recria e engorda de bovinos com essas espécies num período de 18 a 22 meses. Ainda em Ponta Grossa, PR, Postiglioni (1990), numa avaliação sob pastejo, concluiu que a Hemarthria altissima cv. Roxinha é perfeitamente adaptada às condições edafoclimáticas da região dos Campos Gerais do Paraná, pois, além de manter uma carga animal considerável, proporcionou ganhos significativos de peso por hectare.

A possibilidade de utilização de espécies tropicais, principalmente dos gêneros Brachiaria e Setaria, nos sistemas de produção de gado para corte na região dos Campos Gerais do Paraná, assim como nas regiões localizadas mais ao sul do Estado, tem sido freqüentemente questionada pelos criadores e produtores que estão buscando melhorar os índices de produtividade dos sistemas de produção dessas regiões.

O objetivo deste estudo foi avaliar, durante três anos, a capacidade de suporte de sete gramíneas tropicais e subtropicais na região dos Campos Gerais do Paraná, submetidas a pastejo contínuo com novilhos mestiço Canchim, observando-se o desempenho animal e a produção total de carne.

\section{MATERIAL E MÉTODOS}

O estudo foi conduzido em área do IAPAR, em Ponta Grossa, região dos Campos Gerais do Paraná $\left(25^{\circ} 13^{\prime}\right.$ de latitude Sul, $50^{\circ} 1^{\prime}$ de longitude Oeste, altitude de 880 metros), no período de 1992 a 1994. Conforme a classificação de Köppen, o clima da região se enquadra na variedade $\mathrm{Cfb}$, temperado sem estação seca, com temperatura média anual de $17,6^{\circ} \mathrm{C}$, média das máximas $24,3^{\circ} \mathrm{C}$ e média das mínimas de $8,5^{\circ} \mathrm{C}$. A precipitação anual é de $1.400 \mathrm{~mm}$, sendo as chuvas mais freqüentes no período de primavera-verão e mais escassas no outono. O solo é classificado como Latossolo Vermelho-Escuro, de textura média. Análises efetuadas antes da instalação do experimento revelaram as seguintes características: pH (em água) 4,5; fósforo disponível (ppm) 1,0; potássio (meq \%) 0,15; Ca+Mg (meq\%) 1,3; Al trocável (meq\%) 1,5 e matéria orgânica (\%) 2,3. No ano da instalação do experimento, além da calagem feita no preparo do solo, na quantidade de $3 \mathrm{t} / \mathrm{ha}$ de calcário dolomítico, toda a área experimental foi adubada no plantio com $300 \mathrm{~kg} / \mathrm{ha}$ da fórmula 10-20-10. Anualmente foi feita uma adubação de manutenção com $200 \mathrm{~kg} / \mathrm{ha}$ da mesma fórmula.

As gramíneas avaliadas foram: Hemarthria altissima cv. Flórida, Hemarthria altissima cv. Roxinha, Paspalum notatum (capim IPEAME), Setaria anceps cv. Kazungula, Brachiaria brizantha cv. Marandu, Cynodon dactylon cv. coastcross-1 e Acroceras macrum (capim-do-nilo). O delineamento experimental utilizado foi o de blocos casualizados, com duas repetições. A significância dos efeitos dos tratamentos sobre os ganhos de peso vivo/ha, ganho diário/animal e animais/dia/ha foi obtida pelo teste F, conforme Steel \& Torrie (1960) e Pimentel-Gomes (1970). Adotou-se o sistema de pastejo contínuo. Os pastos foram estabelecidos em piquetes com tamanho de 2,0 a 2,5 ha. Além dos animais-testes ou permanentes (12 por tratamento), animais adicionais ou de equilíbrio entraram ou saíram para manter os pastos na altura desejada, utilizando-se a técnica de pastejo put and take preconizada por Mott \& Lucas (1952). Procurou-se manter o capim IPEAME a uma altura de 15 a $20 \mathrm{~cm}$, as hemártrias, coastcross-1, braquiária Marandu e capim-do-nilo com 25 a $30 \mathrm{~cm}$, e a setária com $35 \mathrm{a} 40 \mathrm{~cm}$.

Foram utilizados três grupos de animais ao longo dos três anos, com entrada nos pastos no início da primavera e permanecendo até fins de outono. O primeiro grupo, animais machos castrados, mestiços Canchim, com 10 meses de idade e peso médio de $170 \mathrm{~kg}$ quando entraram nos pastos, e 300 a $320 \mathrm{~kg}$ quando saíram. Os outros dois grupos utilizados eram animais com 18 meses de idade e peso médio de $300 \mathrm{~kg}$ quando entraram e 450 a $530 \mathrm{~kg}$ quando saíram dos pastos. Mensalmente, antes da pesagem dos animais, foram feitas amostragens dos pastos para se estimar a quantidade de forragem disponível. As amostragens foram feitas em 15 pontos diferentes de cada piquete, através de cortes com tesoura, deixando-se um resíduo de 5 a $10 \mathrm{~cm}$ para espécies estoloníferas e/ou rizomatosas e 10 a $15 \mathrm{~cm}$, para cespitosas. Das amostras coletadas, foram feitas subamostras para determinações de proteína bruta e digestibilidade in vitro da matéria seca (DIVMS).

\section{RESULTADOS E DISCUSSÃO}

\section{Ganhos de peso por animal}

Os ganhos diários de peso vivo por animal são apresentados na Tabela 1 . Verifica-se que a hemártria 
Flórida e o capim-do-nilo não diferiram entre si e proporcionaram ganhos individuais significativamente maiores que hemártria Roxinha, setária Kazungula e capim IPEAME, não sendo superiores aos ganhos proporcionados pela braquiária Marandu e coastcross-1. O desempenho dos animais nas sete gramíneas foi estacional e relacionado com os teores protéicos e da DIVMS encontrados nas espécies. As Figs. 1 e 2 ilustram os ganhos individuais dos animais e os valores médios dos teores de proteína bruta e DIVMS apresentados pelas sete gramíneas durante a primavera, verão e outono. Na primavera, época de rebrote, todas as gramíneas apresentaram bom valor nutritivo, proporcionando ganhos acima de $1 \mathrm{~kg}$ por animal/dia.

Hemártria Flórida e capim-do-nilo foram as gramíneas que apresentaram forragem com melhor DIVMS, proporcionando também os melhores ganhos individuais.

As sete gramíneas demonstraram uma redução na concentração de proteína bruta e DIVMS acompanhada de declínio nos ganhos diários dos animais conforme sucediam-se as estações do ano, primavera, verão e outono (Figs. 1 e 2 ), fatos esses provavelmente associados às variações estacionais na estrutura das espécies avaliadas, que, através de exame visual, sempre evidenciaram um decréscimo na relação folha-caule a partir do verão até o outono, época em que atingiam a maturação.

As forrageiras em geral ao atingirem o estádio de florescimento e maturação apresentam um decréscimo na relação folha-caule, verificando-se uma

TABELA 1. Ganho de peso diário por animal em sete gramíneas de estação quente no período de 1992/94. IAPAR, Ponta Grossa, PR.

\begin{tabular}{lcccc}
\hline Gramínea & 1992 & 1993 & 1994 & Média $^{1}$ \\
\hline & -------- & $($ g/animal/dia $)$ & -------- \\
Hemártria Flórida & 745 & 594 & 657 & $665 \mathrm{a}$ \\
Capim-do-nilo & 775 & 475 & 710 & $653 \mathrm{a}$ \\
Braquiária Marandu & 650 & 526 & 644 & $607 \mathrm{ab}$ \\
Coastcross-1 & 625 & 519 & 632 & $592 \mathrm{ab}$ \\
Capim IPEAME & 478 & 436 & 410 & $411 \mathrm{~b}$ \\
Hemártria Roxinha & 510 & 314 & 410 & $411 \mathrm{~b}$ \\
Setária Kazungula & 498 & 397 & 243 & $379 \mathrm{~b}$
\end{tabular}

${ }^{1}$ Médias acompanhadas de mesmas letras não diferem entre si pelo teste de Tukey $(\mathrm{P}<0,05)$

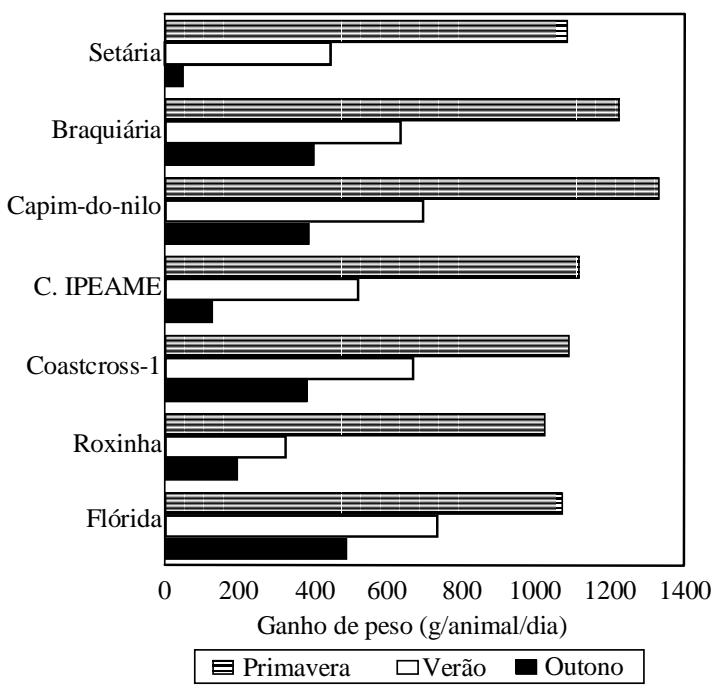

FIG. 1. Ganho de peso diário (g/animal/dia) de bovinos mantidos em pastagens de gramíneas de estação quente por estação do ano. IAPAR, Ponta Grossa, PR, 1992/94.
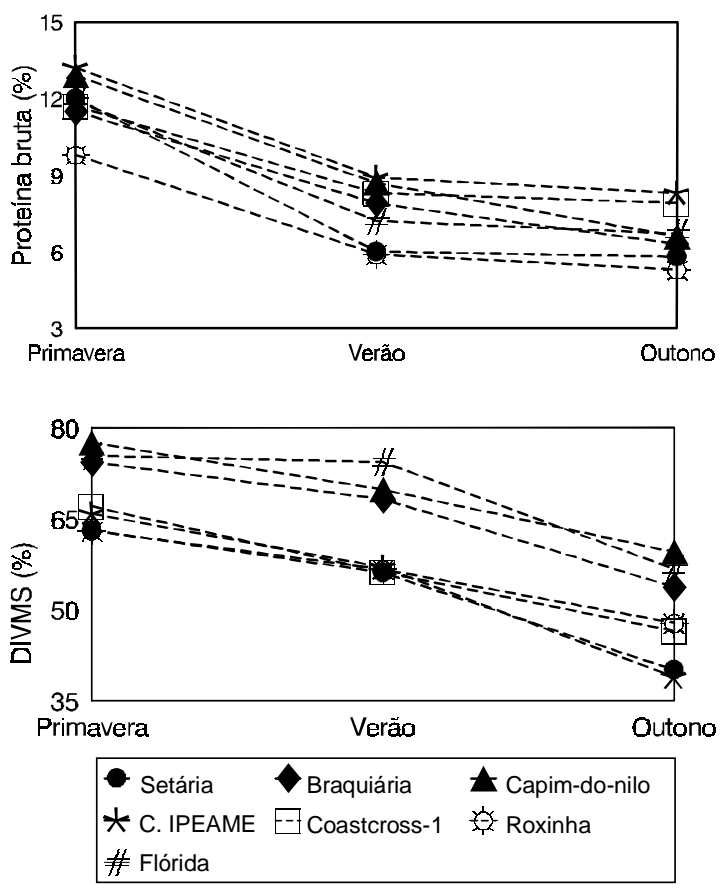

FIG. 2. Valores médios estacionais de proteína bruta e digestibilidade in vitro da matéria seca (DIVMS) em 7 gramíneas de estação quente. IAPAR, Ponta Grossa, PR, 1992/94.

Pesq. agropec. bras., Brasília, v.35, n.3, p.631-637, mar. 2000 
redução na qualidade das diferentes frações da planta. A densidade de folhas em plantas forrageiras é uma característica estreitamente ligada à qualidade, em função de que há uma correlação positiva entre a porcentagem de folhas em uma dada espécie e a composição mineral, protéica e digestibilidade da matéria orgânica (Reid et al., 1959).

Setária Kazungula e hemártria Roxinha foram as gramíneas que apresentaram maior variação estacional com relação a valor nutritivo e desempenho dos animais, apresentando teores de proteína bruta e DIVMS críticos no outono, período em que ocorreu um acúmulo de talos e material morto nas áreas formadas com essas espécies, sugerindo necessidade de adoção de uma maior pressão de pastejo com as mesmas no verão, e evitando-se desta forma a sobra de material menos digestível para os animais.

\section{Animais-dia/hectare/ano}

A capacidade de suporte das sete gramíneas, em cada ano da avaliação e na média dos três anos em que foi conduzido o experimento, é apresentada na Tabela 2. Hemártria Roxinha, que proporcionou uma capacidade de suporte similar ao capim IPEAME $(\mathrm{P}>0,05)$, foi superior $(\mathrm{P}<0,05)$ às outras espécies. Capim IPEAME, hemátria Flórida, capim-do-nilo, coastcross-1, setária Kazungula e braquiária Marandu não diferiram significativamente com relação à capacidade de suporte $(\mathrm{P}>0,05)$. A capacidade de suporte das gramíneas avaliadas também

TABELA 2. Número de animais-dia/ha em sete gramíneas de estação quente no período de 1992/94. IAPAR, Ponta Grossa, PR.

\begin{tabular}{lcccc}
\hline Gramínea & 1992 & 1993 & 1994 & Média $^{1}$ \\
\hline & -------- & (animais-dia/ha) & -------- \\
Hemártria Roxinha & 596 & 1.159 & 992 & $915 \mathrm{a}$ \\
Capim IPEAME & 574 & 729 & 701 & $668 \mathrm{ab}$ \\
Hemártria Flórida & 675 & 628 & 540 & $614 \mathrm{~b}$ \\
Coastcross-1 & 623 & 628 & 540 & $614 \mathrm{~b}$ \\
Setária Kazungula & 502 & 599 & 602 & $567 \mathrm{~b}$ \\
Capim-do-nilo & 579 & 598 & 487 & $554 \mathrm{~b}$ \\
Braquiária Marandu & 494 & 578 & 427 & $499 \mathrm{~b}$ \\
\hline 1 Médias acompanhadas de mesmas letras não diferem entre si pelo teste de \\
Tukey (P<0,05).
\end{tabular}

variou, com diferenças mais ou menos acentuadas entre os anos de avaliação. Em média, o que se verificou foi um pequeno aumento na capacidade de suporte de ano para ano com a setária, ocorrendo o inverso com a hemártria Flórida. As demais gramíneas apresentaram valores crescentes do primeiro para o segundo ano, decrescendo no terceiro e último ano da avaliação (Tabela 2 e Fig. 3). As flutuações na capacidade de suporte das gramíneas, verificadas ao longo dos três anos de estudo, estão associadas às variações encontradas de ano para ano com a quantidade de forragem disponível nos pastos, sendo mais evidente essas relações nas hemártrias, Roxinha e Flórida, na coastcross-1, capim-do-nilo e braquiária Marandu.

A disponibilidade de matéria seca por animal/dia e as pressões de pastejo verificadas com as sete gramíneas ao longo dos três anos da avaliação são apresentadas na Tabela 3.
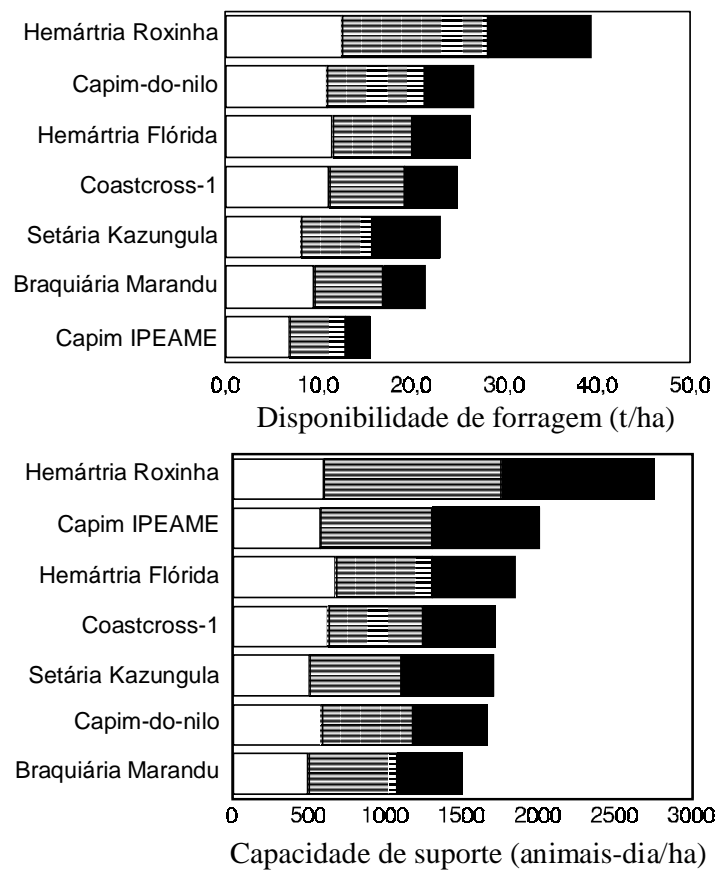

$\square 1992 \boxminus 1993 \square 1994$

FIG.3. Disponibilidade anual de forragem e animais-dia/ha/ano, em pastagens de gramíneas de estação quente. IAPAR, Ponta Grossa, PR, 1992/94. 
Os dados revelam variações entre espécies e de forma mais acentuada entre os anos de estudo. No ano logo após a implantação de todas as gramíneas, a oferta de forragem foi maior, verificando-se pressões de pastejo mais leves, modificando-se os valores nos anos seguintes, com menor disponibilidade de matéria seca e aumento das pressões de pastejo, sobretudo nas áreas com o capim IPEAME.

O capim IPEAME, embora tenha reduzido a disponibilidade de matéria seca no terceiro ano de avaliação, não diminuiu a capacidade de suporte, resistindo a pressões de pastejo altas, o que demonstra, quando submetido a um pastejo mais intenso, uma adaptação estrutural, de forma a reduzir a severidade relativa de desfolha, aumentar a densidade populacional de perfilhos menores ou mais prostrados, e assim maior tolerância a pressões de pastejo mais elevadas. Desfolhas mais freqüentes e intensas, seja por corte ou pastejo, geralmente reduzem o crescimento da pastagem (Anslow, 1967), mas nem sempre reduzem a quantidade de forragem colhida. Reduções em crescimento a partir de desfolhas mais frequientes e intensas podem ser total ou parcialmente compensadas por uma melhor utilização da forragem acumulada e, portanto, por redução nas perdas de forragem não colhida, segundo Biercham \& Hodgson (1983), citados por Pedreira \& Silva (1997).

A braquiária Marandu foi a gramínea com a menor capacidade de suporte (499 animais-dia/ha/ano), mantendo em média (1,8 cab./ha). Além das adubações de manutenção não serem adequadas às suas exigências, as temperaturas baixas, sobretudo à noi- te, durante a primavera e o outono, também limitaram o potencial forrageiro, determinando uma capacidade de suporte abaixo do seu potencial. Nas avaliações sob pastejo com a braquiária Marandu em regiões de clima mais quente, os resultados evidenciam uma capacidade de suporte da cultivar superior às obtidas neste trabalho: em Campo Grande, MS, 2,8 cab./ha (Nunes et al., 1984), e 2,4 cab./ha (Euclides et al., 1993); em Nova Odessa, SP, 2,5 cab./ha (Lourenço et al., 1996).

\section{Ganhos de peso vivo por unidade de área}

A produção de carne ou os ganhos de peso vivo por hectare proporcionados pelas sete gramíneas são apresentados na Tabela 4. As produções são provenientes do produto: animais/dia/ha $\mathrm{x}$ ganho/animal/dia. Hemártria Flórida, capim-do-nilo e hemártria Roxinha produziram maiores pesos vivos por hectare do que a setária Kazungula $(\mathrm{P}<0,05)$, entretanto suas produções não diferiram $(\mathrm{P}>0,05)$ das obtidas com as gramíneas: coastcross-1, capim IPEAME, e braquiária Marandu.

Observando os resultados apresentados por Zimmer \& Euclides Filho (1997), verifica-se que os ganhos de peso vivo proporcionados pelas espécies avaliadas - sobretudo no ano da implantação - são similares ou superiores à maioria das espécies de estação quente cultivadas nas regiões de pecuária de corte brasileira, demonstrando que a região dos Campos Gerais apresenta bom potencial para recria e engorda de bovinos no pasto, sobretudo mediante sistemas de produção constituídos de pastos de verão com pastos de estação fria.

TABELA 3. Disponibilidade de matéria seca e pressão de pastejo em sete gramíneas de estação quente, período 1992/94. IAPAR, Ponta Grossa, PR.

\begin{tabular}{|c|c|c|c|c|c|c|}
\hline \multirow[t]{2}{*}{ Gramínea } & \multicolumn{3}{|c|}{ Matéria seca/animal/dia (kg) } & \multicolumn{3}{|c|}{ Pressão de pastejo (\%) } \\
\hline & 1992 & 1993 & 1994 & 1992 & 1993 & 1994 \\
\hline Hemártria Roxinha & 21,4 & 13,5 & 11,2 & 7,1 & 4,5 & 3,7 \\
\hline Hemártria Flórida & 17,1 & 13,7 & 11,5 & 5,7 & 4,5 & 3,8 \\
\hline Capim-do-nilo & 18,9 & 17,6 & 10,7 & 6,3 & 5,9 & 3,6 \\
\hline Capim IPEAME & 12,1 & 8,2 & 3,8 & 4,0 & 2,7 & 1,3 \\
\hline Braquiária Marandu & 19,4 & 12,8 & 10,6 & 6,4 & 4,3 & 3,5 \\
\hline Setária Kazungula & 16,3 & 12,8 & 12,0 & 5,4 & 4,3 & 4,0 \\
\hline Coastcross-1 & 17,9 & 13,0 & 12,0 & 5,9 & 4,3 & 4,0 \\
\hline
\end{tabular}


TABELA 4. Ganhos de peso vivo em $\mathrm{kg} / \mathrm{ha} / \mathrm{ano} \mathrm{em}$ sete gramíneas de estação quente no período de 1992/94. IAPAR, Ponta Grossa, PR.

\begin{tabular}{|c|c|c|c|c|}
\hline \multirow[t]{2}{*}{ Gramínea } & \multicolumn{4}{|c|}{ Ganho de peso vivo (kg/ha/ano) } \\
\hline & 1992 & 1993 & 1994 & Média $^{1}$ \\
\hline Hemártria Flórida & 486 & 363 & 378 & $409 a$ \\
\hline Capim-do-nilo & 598 & 255 & 338 & $397 \mathrm{a}$ \\
\hline Hemártria Roxinha & 379 & 361 & 416 & $385 a$ \\
\hline Capim IPEAME & 385 & 345 & 405 & $377 \mathrm{ab}$ \\
\hline Coastcross- 1 & 453 & 316 & 295 & $354 a b$ \\
\hline Braquiária Marandu & 392 & 289 & 239 & $306 a b$ \\
\hline Setária Kazungula & 305 & 208 & 157 & $223 b$ \\
\hline
\end{tabular}

É importante ressaltar a acentuada redução nos ganhos de peso vivo/ha verificada ao longo do período experimental com as espécies: capim-do-nilo, braquiária Marandu, coastcross-1 e setária Kazungula, ficando evidente que uma das limitações para cultivo dessas espécies na região seria a rápida degradação de suas pastagens. A setária Kazungula produziu no terceiro ano apenas $51 \%$ dos ganhos proporcionados no primeiro ano, capimdo-nilo, 56,5\%, braquiária Marandu, $61 \%$ e coastcross- $1,65 \%$. O comportamento dessas gramíneas está intimamente associado ao efeito de geadas, deficiência de nutrientes ou manejo inadequado, fatores que ao longo dos anos contribuem de forma significativa para que ocorra a degradação dos pastos perenes.

Hemártria Roxinha e capim IPEAME foram as espécies que apresentaram uma melhor regularidade nas produções de carne durante o período experimental, variando pouco seus rendimentos de ano para ano, além de proporcionarem aumento nos ganhos de peso vivo por unidade de área no terceiro ano de estudo.

Embora exigentes em nutrientes ou manejo, as gramíneas capim-do-nilo, braquiária Marandu, hemártria Flórida e coastcross-1 demonstraram ser mais eficientes com relação ao item terminação de bovinos. A Fig. 4 ilustra o melhor desempenho dos novilhos na fase de engorda mantidos nessas espécies, os quais atingiram peso para abate mais rapidamente, evidenciando como vantagem sobre as

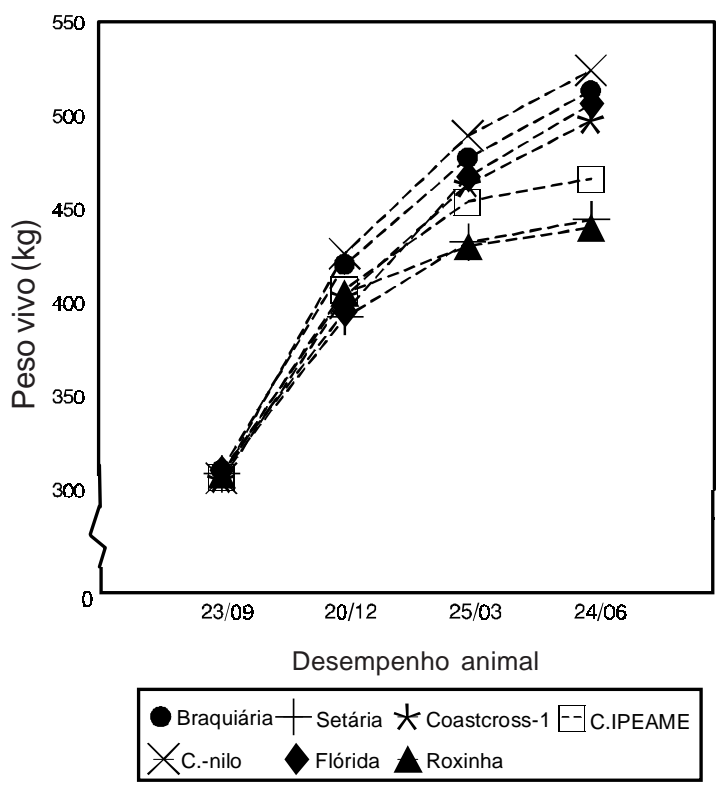

FIG. 4. Desempenho de novilhos na fase de engorda em pastagens de gramíneas de estação quente. IAPAR, Ponta Grossa, PR, 1992/94.

demais a liberação mais rápida da área para a entrada de outro grupo de animais.

\section{CONCLUSÕES}

1. O desempenho animal nos pastos de hemártria Flórida e capim-do-nilo é superior em relação ao capim IPEAME, hemártria Roxinha e setária Kazungula.

2. Hemártria Roxinha suporta maior número de animais por unidade de área quando comparada com hemártria Flórida, coastcross-1, setária Kazungula, capim-do-nilo e braquiária Marandu.

3. Entre as sete gramíneas avaliadas, sob os aspectos produção e persistência, as melhores opções para sistemas extensivos com gado de corte na região dos Campos Gerais do Paraná são: hemártria Flórida, hemártria Roxinha e capim IPEAME.

4. Setária Kazungula, capim-do-nilo, braquiária Marandu e coastcross-1 também demonstram potencial para produção de carne na região dos Cam- 
pos Gerais do Paraná, entretanto necessitam maior quantidade de nutrientes e manejo adequado às suas características morfofisiológicas.

\section{REFERÊNCIAS}

ANSLOW, R.C. Frequency of cutting and sward production. Journal of Agricultural Science, Cambridge, Grã-Bretanha, v.68, p.377-384, 1967.

EUCLIDES, V.P.B.; ZIMER, A.H.; VIEIRA, A.; OLIVEIRA, M.P. Evaluation of Brachiaria decumbens and Brachiaria brizantha under grazing. In: INTERNATIONAL GRASSLAND CONGRESS, 17., 1993, Palmerston North. Proceedings. Palmerstone North : New Zealand Grassland Association, 1993. p.1997-1998.

LOURENÇO, J.A.; CARRIEL, J.M.; BEISMAN, A.D Desempenho de bovinos Nelore em pastagens de Brachiaria brizantha associada à Leucaena leucocephala. In: RENIÃO ANUAL DA SOCIEDADE BRASILEIRA DE ZOOTECNIA, 33., 1996, Fortaleza. Anais. Fortaleza : Sociedade Brasileira de Zootecnia, 1996. p.10-12.

MOTT, G.O.; LUCAS, H.L. The design, conduct and interpretation of grazing trials on cultivated and improved pastures. In: INTERNATIONAL GRASSLAND CONGRESS, 6., 1952, State College. Proceedings. State College, Pennsylvania : State College Press, 1952. p.1340-1345.

NUNES, S.G.; BOOK, A.; PENTEADO, M.I. de O.; GOMES, D.T. Brachiaria brizantha cv. Marandu. Campo Grande : Embrapa-CNPGC, 1984. 31p. (Embrapa-CNPGC. Documentos, 21).

PEDREIRA, C.G.S.; SILVA, S.C. Princípios de ecologia aplicados ao manejo da pastagem. In: SIMPÓSIO SOBRE ECOSSISTEMA DE PASTAGEM, 3., 1997, Jaboticabal. Anais. Jaboticabal : UNESP, 1997. p.1-61.
PIMENTEL-GOMES, F. Curso de Estatística Experimental. 3.ed. Piracicaba : ESALQ, 1970. 404p.

POSTIGLIONI, S.R. Hemarthria altissima: novas cultivares recomendadas pela pesquisa. Londrina : IAPAR, 1984. 2p. (IAPAR. Informe da Pesquisa, 52).

POSTIGLIONI, S.R. Hemarthria altissima: uma forrageira para a região dos Campos Gerais do Paraná. Londrina : IAPAR, 1983. 13p. (IAPAR. Circular, 36).

POSTIGLIONI, S.R. Métodos de implantação do cornichão (Lotus corniculatus L.) em pastagens nativas da região dos Campos Gerais do Paraná. Londrina : IAPAR, 1995. 17p. (IAPAR. Boletim Técnico, 46).

POSTIGLIONI, S.R. Recria de bezerros em Hemarthria altissima cv. IAPAR 35-Roxinha. Londrina : IAPAR, 1990. 9p. (IAPAR. Informe da Pesquisa, 93).

POSTIGLIONI, S.R.; PICANÇO, R.C. Avaliação sob pastejo de três gramíneas subtropicais e do campo nativo na região dos Campos Gerais do Paraná. Pesquisa Agropecuária Brasileira, Brasília, v.14, n.1, p.53-61, jan. 1979.

REID, J.T.; KENNEDY, W.T.; TURK, K.L.; SLACK, S.; TRIMBERGER, G.W.; MURPHY, R.P. Symposium on forage evaluation. What is forage quality from the animal "stand point." Agronomy Journal, Madison, v.51, p.213-216, 1959.

STEEL, R.G.D.; TORRIE, J.H. Principles and procedures of statistics with special references to the biological sciences. New York : McGraw-Hill, 1960. 480p.

ZIMMER, H.A.; EUCLIDES FILHO, K. As pastagens e a pecuária de corte brasileira. In: SIMPÓSIO INTERNACIONAL SOBRE PRODUÇÃO ANIMAL EM PASTEJO, 1., 1997, Viçosa. Anais. Viçosa : UFV-Departamento de Zootecnia, 1997. p.349-379. 